\title{
THE INFLUENCE OF PURPOSE IN LIFE ON LIFE SATISFACTION AMONG MOTORCYCLE OPERATORS FROM UGENYA AND UGUNJA SUB - COUNTIES IN SIAYA COUNTY, KENYA
}

\author{
${ }^{1}$ Fredrick Odhiambo Oyugi, ${ }^{2}$ Rev (Dr.) Hubert Pinto and ${ }^{3}$ Francis Ehiamhen Obaweiki \\ ${ }^{1}$ Archdiocese of Kisumu, P. O. Box 795 Kisumu, 40100, Kenya. \\ ${ }^{2}$ Institute of Youth Studies, Tangaza University College, \\ Catholic University of Eastern Africa, P.O. Box 62157 Nairobi, 00200, Kenya \\ ${ }^{3}$ Department of Psychology, Faculty of Arts and Social Science, The Catholic University of Eastern \\ Africa, P.O. Box 62157 Nairobi, 00200, Kenya
}

DOI: 10.46609/IJSSER.2020.v05i09.007 URL: https://doi.org/10.46609/IJSSER.2020.v05i09.007

\begin{abstract}
Purpose in life has been found through studies to be correlated to life satisfaction. The purpose of this study was to examine the influence of purpose in life on life satisfaction among youth motorcycle operators (Boda-Boda) from Ugenya and Ugunja sub -counties in Siaya County aged between 18 and 35 years old. This study was anchored on Logotherapy by Viktor Emil Frankl. The study adopted a correlational design and used purposive and convenience sampling to select 285 ( N=285) motorcycle operators. Purpose in life test (PIL) and satisfaction with life scale (SWLS) were the research instruments used for the study. The data were analyzed using descriptive and inferential analysis (Cronbach's $\alpha$, Pearson's r, t-test, one way ANOVA and Tukey Post Hoc Test multiple comparison) with the application of statistical package for social sciences (SPSS) IBM version 21. The result indicated that there was a positive significant correlation between purpose in life and life satisfaction among motorcycle operators from Ugenya and Ugunja Sub - Counties in Siaya County $(\mathrm{N}=285, \mathrm{r}=.29 * * \mathrm{P}<.01)$. The overall mean score for motorcycle operators on purpose in life $(M=103.99, S D-18.41)$ fell in the category of "somehow "uncertain purpose in life", and overall mean score on life satisfaction $(M=23.23, S D$ 5.23 ) in the "slightly satisfied". The "somehow uncertain purpose in life" and "slightly satisfied with life" among the sampled motorcycle operators showed an existence of an existential vacuum among motorcycle operators, which calls for logotherapy counseling among the motorcycle operators.
\end{abstract}

Key words: Logotherapy, purpose in life, life satisfaction, boda-boda, Ugunja, Ugenya, Siaya 
International Journal of Social Science and Economic Research

ISSN: 2455-8834

Volume:05, Issue:09 "September 2020"

\section{INTRODUCTION AND BACKGROUND}

Life projections of youth in today ${ }^{\text {ec }}$ world are far from being assured, this is because most of the youth have no awareness what their occupation would be despite the world emphasis on educational achievements. It is common to encounter many youth who have achieved specific careers, lack job opportunities or engage in casual jobs such as touts, charcoal venders and motorcycle operation among others which they have no training or limited knowledge. In such scenarios, some youth revisit "purpose in life" and formulate clear aspirations for "life satisfaction". Such youth are motivated to be productive members of the society through personal initiatives thus venturing into self-employment, small businesses and opportunities at disposal. These youth would probably find satisfaction in life in any job available at their disposal. While other youth wonder what to do with their lives in cases where they cannot find alternative job opportunities. In fact, such youth idle all day long without a "purpose in life" in wait for some unknown persons or organizations to offer them some job opportunities. They eventually end up experiencing existential vacuum which in turn may lead them to deviant behaviors and psychological maladjustments (Anxiety, anger, depression and suicide).

Youth is a specified time in life when young people start realizing their aspirations acquired through education, vocational trainings and cultural practices. It is a time for idealism when young people take advice about seeking fulfillment and passion in life seriously (Damon, 2008). It is a time to gauge the kind of purpose in life the youth have developed and or still developing in life. This is a period to start assuming economic independence through employment and careers like police, advocate, doctor and nurse, or self-employment such as motorcyclist, fruit vendors, carpenter and mason. It is a period of finding a place in society as productive members through marriage and leadership responsibilities among other involvements. This age is marked with exploration of "purpose in life" aimed at "life satisfaction".

Youth is a period of human development from childhood to adulthood. Youth is defined differently by institutions and countries. For example in Kenya, youth are individuals in the republic of Kenya who have attained the age between 18 and 35 years (GOK, 2010). A look at this age bracket probably indicates these are people either in or out of school, and probably have reached different levels of education as primary, secondary and or college graduates. They are either job seeker's, self-employed or employed. At the same time their marital status is either single or married. Due to various reasons and motivations such as preference, quick money making, availability and may be the only option in life, a number of youth in this age bracket (18-35) have embraced public motorcycle transportation as an occupation. In fact it may be their way towards achieving "purpose in life" and "life satisfaction". Studies carried out by Kisaalita and Kibalama (2007), Odumosu and Yaro (2008) established that majority of motorcycle operators are youth aged between 16 and 35 years. Motorcycle operators in Kenya are commonly 


\section{International Journal of Social Science and Economic Research}

ISSN: $2455-8834$

Volume:05, Issue:09 "September 2020"

known as Boda-Boda (Border to Border). Boda-Boda is a term coined by cyclists who transported passengers and goods across the borders of Kenya and Uganda. In this study the two terms motorcycle operator and Boda-Boda are used interchangeably.

Youth are at the appropriate age (18 -35) to develop and actuate "purpose in life", which if well sought could result in goal achievements, personal happiness and usefulness to the society. In fact, youth who are achieving "purpose in life" are somehow generally perceived to be in the right path to "life satisfaction", while lack of "purpose in life" at youthful age could possibly be manifested in meaninglessness or existential vacuum which is portrayed in boredom, depression and anxiety disorders (Frankl, 1959).

Age is a factor in life that affects all areas of human existence including people in motorcycle operation. The perception of "purpose in life" and "life satisfaction" among motorcycle operators may possibly differ depending on their age. For example, younger motorcycle operators on one hand would enjoy motorcycle riding for fun and exploration, while on the other hand, older motorcycle operators would go into motorcycle operation as a job with an aim to source for funds for livelihood. At times, one would wonder whether an age difference possibly predicts "purpose in life" and "life satisfaction" among motorcycle operators. For instance, it is common to notice both younger and older motorcyclist in Siaya County engage in excessive alcohol use and over speeding which places them at risks of fatal accidents. Therefore, the interest of this study is to establish whether age could possibly predict "purpose in life" and "life satisfaction" among the motorcycle operators in Ugenya and Ugunja Sub-Counties of Siaya County.

Motorcycle transport (Boda-Boda) is operated by people of different educational levels namely: primary, secondary and or college graduates. Education is a fundamental right which must be provided to every Kenyan irrespective of tribe, culture, gender, ethnicity and political affiliation (International Bureau of Education - UNESCO, 2006). Accordingly, youth have the right to access relevant education and training (The constitution of Kenya, 2010, 39). Education is therefore expected to prepare and equip the youth with knowledge, skills and expertise necessary to enable them collectively and individually play an effective role in an individual ${ }^{\text {le }} \mathrm{s}$ life and community as a whole. Furthermore, education should enable people to engage in activities that enhance "purpose in life" and "life satisfaction". Due to the fact that motorcycle operators belong to different educational levels, their "purpose in life" and "life satisfaction" may possibly vary. It is possible that the difference in educational level of motorcycle operators could be the point of variance for perception of "purpose in life" and "life satisfaction". It would probably be of interest to evaluate how educational level aid motorcyclists to exercise their "meaning in life", "freedom of will" and "will to meaning" in terms of their use of the income earned from the logotherapy point of view. For example, it is a common remark by primary, secondary and or college graduate motorcycle operators to say that "I have all the freedom to use my money the way I want because it is from my sweat, it is quick money that motivated me to be a motorcycle operator". Therefore, of interest to this study was to find out the influence of educational level on 


\section{International Journal of Social Science and Economic Research}

ISSN: $2455-8834$

Volume:05, Issue:09 "September 2020"

"purpose in life" and "life satisfaction" among motorcycle operators from Ugenya and Ugunja sub - counties in Siaya County.

The age bracket between 18 and 35 years old confers another status in human development namely marital status. Among the motorcycle operators, there are those either single or married. Marriage brings an added responsibility to an individual who has the obligation to provide for family needs like food, shelter, clothing and education. The conception of "purpose in life" and "life satisfaction" among single and married persons may possibly differ considerably across different categories of persons. For example, in the category of motorcycle operators, a single motorcycle operator would probably use his / her collection of the day for enjoyment such as drinking with friends and buying fancy smart phone while a married motorcycle operator who has the duty to provide food to the family and pay fee for their children would use the collection with lots of caution. "Purpose in life" which is achievement of goals and usefulness in the community would probably not be perceived differently by single and married motorcycle operators. "Life satisfaction" which is an indicator of ,apparent quality of life (Veenhoven, 1996) would also be perceived not differently by single and married motorcycle operators. For instance, it is common to observe both single and married motorcycle operators engage in similar life styles such as excessive alcohol use and claim satisfaction with life. Therefore, this study aimed at examining whether marital status does not have an impact on "purpose in life" and "life satisfaction" among motorcycle operators.

Among the Kenya vision 2030, whose overarching vision is to make Kenya a globally competitive and prosperous nation with a high quality of life by 2030, in its second medium term plan (MTP) of vision 2030: 2013- 2017, one agenda is employment creation especially among youth (Kenya Vision 2030). This has been appraised by the introduction and subsequent increase of motorcycle transport sector as can be observed across all the 47 Counties in Kenya, including Siaya County. Motorcycle transport sector has created employment to a number of people in Kenya and other countries such as Uganda, Rwanda and Nigeria (Oluranti, 2011). As it can be deduced, this sector has provided a source of income to the many people who otherwise would remain jobless or idle all day long without a "purpose in life". Hence, there is a possibility that such people would indulge themselves in deviant behaviors such as theft, robbery, drugs and alcohol abuses as a probable means of life satisfaction.

Today, as can be observed, thousands of people are involved in Boda-Boda as means of personal transportation and goods as well as an employment to sustain livelihood. In global perspective, motorbikes are the primary means of motorized transport. Statistics released by the MOTC (2011) (Ministry of Transportation and Communication), indicated that Taiwan has become the home of the highest motorcycle density in the world, with 419.3 motorcycles per square kilometre, while China, India, Indonesia, and Vietnam are the other four largest motorbike sellers in the world (Porter, 2013). In Vietnam, motorbike use is extremely high due to a lack of public transport and low income levels that put automobiles out of reach for many (Fujita, 2013). 


\section{International Journal of Social Science and Economic Research}

ISSN: 2455-8834

Volume:05, Issue:09 "September 2020"

The Government of Kenya, Economic Survey (2015) report indicates that motorcycle new registration is one hundred and eleven thousand, one hundred and twenty four for the year 2014 / 2015. Reasonably this is due to introduction of cheap and affordable motorcycles in many Countries of the World such Vietnam, India and China (Porter, 2013). Such is the possible reason for rapid growth of motorcycle transport system in most cities of the World (Nairobi, Kampala and Bujumbura), markets places, urban centers and public vehicle terminus. This is an indication that commercial motorcycle business is becoming dominant across all Counties in Kenya which has absorbed many youth in job placement. In fact motorcycle transportation has eased movement of passengers and goods reaching to their door stops leading to its preference by many people in different parts of the World.

In Siaya County like in many other Counties in Kenya, the rise of motorcycle operation can be attributed to unemployment, quick money making process and poor road network. For example in Siaya County there is substantially no industry where young people can be adequately employed. In addition, Siaya County transportation system is predominantly by road, yet in the entire County only $283.2 \mathrm{Km}$ of roads are tarmacked, $741.3 \mathrm{Km}$ of gravel and $1,161.8 \mathrm{Km}$ of earth roads (Siaya County Integrated Development Plan, 2012) thus making buses and vans (Matatus) public transporters impossible to access many parts of Siaya County especially in some parts of Ugenya and Ugunja Sub- Counties.

Studies carried out about motorcycle and motorcycle operators have been concentrated on the economic viability, fatal accidents and deaths caused by Boda-Boda operators (Everett et al., 2001; Kumar, 2011; Mannering, 1995). However, there is lack of studies on the association between "purpose in life" and "life satisfaction" among youths under the category of motorcycle operators in Siaya County as predicted by age, education and marital status.

Purpose in life (hereafter used interchangeably with purpose and meaning in life) is a concept of logotherapy founded by Viktor Emil Frankl. Logotherapy is a therapy of healing through meaning (Frankl, 1959, 1986, 1992). It is based on the future premise that, whoever has a goal, an aim, an objective, a vision to fulfill in the future can bear with any situation in life (Frankl, 1992). According to Frankl, "purpose in life" is achievement of goals, vision and future task through creating a work or doing a deed, experiencing "nature and culture" or by experiencing another human being in his/her very uniqueness and giving a meaning when confronted with a hopeless situation (Frankl, 1984).

"Purpose in life" is a variable that positive psychology frequently associates with measures of healthy psychological functioning, such as life satisfaction, happiness and functioning as a tool that allows for greater resistance to suffering (Brandstatter et al., 2014; Wnuk, Marcinkowski \& Fobair, 2012). "Purpose in life" is a driving force that focuses on a broad aspect of human life: psychological, spiritual, economic and social well-being. The psychological aspects results into emotional, behavioral cognitive faculties. Bernard (1991), points out that the psychological aspects are portrayed in goal-directedness, achievement, motivation, educational aspirations, 


\section{International Journal of Social Science and Economic Research}

ISSN: $2455-8834$

Volume:05, Issue:09 "September 2020"

healthy expectations, persistence, hopefulness and a sense of compelling future. The spiritual aspects are realized in being connected to the transcendent. While economic caters for the needs of the human being and social promotes relationships.

"Purpose in life" is further described by McKnight and Kashdan (2009) as a central, selforganizing life aim that organizes and stimulates goals, manages behaviors, and provides a sense of meaning, is a concept that directs an individual to a sense of belonging. It is central in that when present, purpose is a predominant theme of a person "e identity. Self-organizing in that it provides a framework for systematic behavior patterns in everyday life (McKnight \& Kashdan, 2009). From this point of view, "purpose in life" is of significant importance for youth who look forward to goal achievements, self-regulation and worthiness in the society (Schemer et al, 2006). Therefore having a "purpose in life" is a key to achieving the fortuitous end envisioned by the positive psychology movement, such as authentic happiness, flow of life and creativity in the society (Damon, Menon \& Bronk, 2003; Frankl, 1959). For this research, purpose in life is based on Frankl's description as having goals, aims, mission and task to fulfill in the future through meaning.

As can be observed in Siaya County and elsewhere, some motorcycle operators in Siaya County seem to have a clear "purpose in life" (Goals achievement). For example, they have managed to build good residential houses while others probably look like they have no clear "purpose in life" at all. For example, a local alcohol (Changaa) seller confidently confirmed that majority of her customers were Boda-Bodas. She added that they drink until some of them are unable to walk back to their homes. This poses the question to whether motorcycle operators in Siaya County do have clear "purpose in life" or is it possible they just don't want to think about it. In addition, can there be an objective perception of "purpose in life" among motorcycle operators in Siaya County?

Every human person in the world yearns for a good life which can be objectively and subjectively perceived from the point of view of shelter, food, clothing, education, leisure and health insurance. Generally, success in life is commonly perceived as the immediate answer to "purpose in life" and "life satisfaction" however failure and suffering in life is commonly seen as lack of "purpose in life" and dissatisfaction in life

"Life satisfaction" is an individual "s overall evaluation of the quality of life according to criteria the individual determines (Diener, Oishi \& Lucas, 2003; Diener, Inglehart \& Tay, 2013). According to Veenhoven (1996) quality of life denotes the presence of conditions deemed necessary for a good life, and the practice of good living as such. For example one can evaluate his/her life as satisfying from material possessions like large areas of land, sufficient food, and health care, wealth and high educational level. "Life satisfaction" is generally an individual's living conditions, ideals, acquisitions and what makes one to be fulfilled (Diener, Emmons, Larsen, \& Griffin, 1985). From the above definitions, "life satisfaction" is surrounded by a number of elements such as age, education, gender, socio- economic (Cohen, Gottlieb \& 


\section{International Journal of Social Science and Economic Research}

ISSN: 2455-8834

Volume:05, Issue:09 "September 2020"

Underwood, 2001), marital status (Diener, Gohm, Suh, \& Oishi, 2000) and physical health.

"Life satisfaction" may differ depending on an individual's age, level of education, marital status and or occupation. These components may possibly predict the level of "life satisfaction" as high or low. Whereas high level of "life satisfaction" would suggest that the "purpose of life" is good and being fulfilled, low level of "life satisfaction" would suggest some shortcomings and sufferings in life. An example is the assessment study on "life satisfaction" among single people (Veenhoven, 2015) which asserted that the difference in "life satisfaction" between those who are single and those with a partner is in fact greater than that expressed between rich and poor. Therefore this study was to determine level of "life satisfaction" among motorcycle operators from Ugenya and Ugunja Sub-Counties in Siaya County in relation to age, level of education and marital status.

Logotherapy which is therapy based on purpose / meaning in life directed towards achieving goals for future task is the focus through which this study was based. Logotherapy transcend beyond "will to pleasure" and "will to power" to "will to meaning" in life at all cost even at the most unbearable conditions (Frankl, 1969). It is intended to treat existential vacuum (noo"genic neurosis) experienced by people in various life circumstances which would possibly include people in motorcycle operation.

Existential vacuum is a state of emptiness or meaninglessness in life. Existential vacuum occurs when people suffer from an inner void and lack of meaning in life (Frankl, 1959). As such existential vacuum may probably lead to lack of "life satisfaction" Such a state of dissatisfaction in life would consequently result to searching for other means of "life satisfaction" such as finding pleasure in overeating, excessive alcohol and drug use, promiscuous sex, anger, anxiety and or depression. Thus, could there be a possibility that among motorcycle operators in Siaya County, those who are observed being involved in increased alcohol abuse, multiple sexual relationships, suicide ideations and marriage separations are experiencing existential vacuum? Furthermore, could lack of "purpose in life" be the cause of dissatisfaction in life. This study examined the kind of correlation that exist between "purpose in life" and "life satisfaction" among youth (Motorcycle operators) in Siaya County.

\section{METHODS}

This study was conducted in Siaya County, Kenya. Two sub-counties were selected because of the heavy presence of boda-boda operators there. The study adopted the quantitative paradigm, using the correlation design. This sampling technique allowed the researcher to get cases that have the required information with respect to the objectives of the study (Mugenda \& Mugenda, 2012).

The population of this study was 1200 motorcycle operators from both Ugenya and Ugunja Sub 
International Journal of Social Science and Economic Research

ISSN: 2455-8834

Volume:05, Issue:09 "September 2020"

- Counties (Siaya County Census Report, 2015). A sample size of 291 participants were conveniently sampled. This study used the 20-item Purpose in Life Test (PIL) scale (Crumbaugh and Maholick, 1969), with a Cronbach"s alpha coefficient of 0.87. Also, the Life Satisfaction Scale (Diener, Emmons, Larsen, \& Griffin, 1985), with a Cronbach"s alpha coefficient of 0.76 was used. This indicated that the instruments of measure in this study had a good reliability.

Data Collection Procedures: The researcher got the approval of the National Commission for Science, Technology and Innovation (NACOSTI) and visit to the Siaya County Commissioner and County director of Education to conduct the study. Data were collected from motorcycle operators from Ugenya and Ugunja Sub - counties in Siaya County from their specific take - off points at market places, shopping centres, major roads, road junctions and bus terminus. The researcher liaised with the elected leaders (motorcycle operators) of different groups and their saving and credit co-operative society (SACCOS) on their meeting days to request for at least 30 to 40 minutes to carry out the research amongst them. After a briefing on the purpose of the study, the researcher was assisted by the group leaders to conduct the study in compliance with salient ethical considerations.

Data Analysis and Presentation: data from 285 participants were analysed using the Statistical Package for Social Sciences (SPSS) version 22. Data were analysed using Pearson"s correlation coefficient analysis to establish the influence of purpose in life on life satisfaction among motorcycle operators from Ugenya and Ugunja Sub - Counties in Siaya County.

\section{RESULTS}

\section{Demographic Information}

The demographic information of the participants were examined to help define the sample demographic characteristics and to give a better understanding of the population in the current study. It was also to provide a basis for comparative analysis by future researchers. Demographic details of the participants of the quantitative strand are summarize and presented in table 1.

Table 1

Demographic Details of the Participants $(N=285)$

\begin{tabular}{llllll}
\hline Characteristics & & Frequency & $\%$ (Freq) & mean & SD \\
\hline \multirow{3}{*}{ Age (years) } & $18-20$ & 45 & 15.8 & & \\
& $21-24$ & 65 & 22.8 & 26.5 & 1.05 \\
& $25-30$ & 91 & 31.9 & &
\end{tabular}


International Journal of Social Science and Economic Research

ISSN: $2455-8834$

Volume:05, Issue:09 "September 2020"

Level of education

$\begin{array}{lll}31-35 & 84 & 29.5\end{array}$

\begin{tabular}{llll} 
& Primary & 132 & 46.3 \\
& Secondary & 108 & 37.9 \\
Marital status & College and above & 45 & 15.8 \\
& & & \\
& Single & 109 & 38.2 \\
Motorcycle specific & Married & 176 & 61.8 \\
& & & \\
& Hired & 180 & 63.2 \\
Location & Owner & 105 & 36.8 \\
& Ugenya & 164 & 56.4 \\
\hline Total & Ugunja & 121 & 41.5 \\
\hline
\end{tabular}

The age of the participants ranged from 18 to 35 years. The mean age was 26.5 with a standard deviation of $1.05(M=26.5, S D=1.05)$. The results of age shows an even distribution of participants across all the age brackets of the study. Out of the 285 participants, $15.8 \%$ were motorcycle operators in age bracket between 18-20 years, $22.8 \%$ were in the age bracket 21-24 years old $31.3 \%$ were in the age bracket of $25-30$ years old, and $28.9 \%$ motorcycle operators were in the age bracket between 31-35 years old.

In regard to educational level, boda-boda operation is dominated by primary school graduates. Out of the 285 who participated, $46.3 \%$ were primary school leavers, $37.9 \%$ secondary school while $15.5 \%$ ) were college and above graduate.

The result of marital status showed that majority of the boda-boda in Ugenya and Ugunja were married as early as the age of 18 years. The results indicated that $61.8 \%$ of boda-boda sampled from Ugenya and Ugunja were married $38.2 \%$ were single.

In respect to motorcycle specifics, two classes boda-boda were encountered in the study: 1) hired motorcycle and; 2) owner operators. The results of the study revealed that hired operators were predominant at $63.2 \%$ while the owner operators $36.8 \%$. This showed that majority of motorcycle operators were not the owners of the motorcycle.

Finally with respect to location $55.7 \%$ motorcycle operators were from Ugenya while $4.3 \%$ were from Ugunja which showed an even preference in both the two sub - counties.

\section{Correlation between Purpose in Life and Life Satisfaction.}

The study hypothesized that, purpose in life has no statistically significant influence on life satisfaction among motorcycle operators from Ugenya and Ugunja sub - counties in Siaya County. The influence of purpose in life on life satisfaction among motorcycle operators from Ugenya and Ugunja sub - counties in Siaya County was examined first with descriptive statistics. 
International Journal of Social Science and Economic Research

ISSN: 2455-8834

Volume:05, Issue:09 "September 2020"

The results is summarized and presented in table 2 .

Table 2

Influence of Purpose in Life on Life Satisfaction

\begin{tabular}{llllll}
\hline Scale & N & Minimum & Maximum & Mean & SD \\
\hline PIL & 285 & 46.00 & 138.00 & 103.99 & 18.41 \\
SWLS & 285 & 7.00 & 34.00 & 23.43 & 5.23 \\
\hline
\end{tabular}

The result in table 2 shows that PIL yielded a mean score of 103.99, a variance of 339.24 and a standard deviation of 18.41. This 103.9 mean translated into a whole number is 104 and the standard deviation of 18. From the interpretation of PIL, a mean score of 104 falls into the category between 92 and 112 which indicated "somehow uncertain purpose in life" (Crumbaugh \& Maholick, 1969).

The result of SWLS' had a mean of 23.43, a variance of 27.33 and a standard deviation of 5.23. Presented into whole numbers, the SWLS sample in this study had a mean of 23 with a deviation of 5. According to interpretation of SWLS, a mean of 23 presents "slightly satisfied with life" (Pivot \& Diener, 1993).

In order to establish the correlation between "purpose in life" and "life satisfaction", Pearson's correlation coefficient product was conducted and the results presented in table 3 .

Table 3

Correlation between Purpose in Life and Life Satisfaction $(N=285)$

\begin{tabular}{lll}
\hline Scale & Purpose in life & $\begin{array}{l}\text { Satisfaction with life } \\
\mathbf{. 2 9 0 * *}\end{array}$ \\
Purpose in life & 1 & 1 \\
Satisfaction with life & .000 & 1 \\
\hline $\mathrm{r}=.290^{* *} \mathrm{P}<.01$ &
\end{tabular}

The results showed that there was a positive significantly correlation between "purpose in life" and "life satisfaction" $\mathrm{r}=.29^{* *}, \mathrm{p}<.01$. Therefore, the hypothesis was not supported. The findings indicated that there is a positive significant correlation between the scores of "purpose in life" and "life satisfaction" among the boda-boda from Ugenya and Ugunja Sub - Counties in Siaya County. The result pointed out that "purpose in life" and "life satisfaction" has influence on each other among the participants. 
International Journal of Social Science and Economic Research

ISSN: $2455-8834$

Volume:05, Issue:09 "September 2020"

\section{DISCUSSION}

The study established that there was a positive significant correlation between "purpose in life" and "life satisfaction" among the participants. This indicated that among the participants, those with clear purpose in life had better life satisfaction as they ply their trade. This result further implied that both purpose in life and life satisfaction affect each other among the sample.

This study is consistent with findings from other studies that there is a significant positive correlation between purpose in life and life satisfaction. For example, Diener, Fujita, Tay and Biswas-Diener (2012), Kim, Sun, Kubzansky, Park and Peterson (2013), and Hill (2014), confirmed that individuals who cultivate a meaningful sense of direction for themselves tend to live longer, experience better physical and mental health, and enjoy happier and more satisfying lives. Further in a more vivid way the result of the present study concurred with previous research which ascertained that having meaning in life is positively associated with happiness and life satisfaction (Park, Park, \& Peterson, 2010; Cohen \& Cairns, 2011). In fact, this finding was in line with Damon (2008) that finding a clear "purpose in life" is essential for achievement of happiness and satisfaction in life. In addition, the relationship between purpose in life and life satisfaction can be summed up in the words of Frankl (1959) observation that those inmates who held belief systems, such as religious faith or conviction about human progress, were far more likely to survive the camp"s hardships and find life satisfaction than those who simply tried to try out their existence. Thus, motorcycle operators who cultivate a strong motivation for their occupation, and freely choose motorcycle operation will probably find meaning in life and minimize mental health related problems (depression and anxiety disorders) associated with lack of purpose in life and life satisfaction. The logotherapy of Frankl (1992) depicts human existence as a call to responsibility towards one"s life, therefore responsible motorcycle operators who are responsible in their work will find life purposeful and satisfying.

\section{CONCLUSIONS AND RECOMMENDATIONS}

The study revealed a positive significant correlation between purpose in life and life satisfaction among motorcycle operators from Ugenya and Ugunja sub - counties in Siaya County. Thus rejecting the fourth and the main objective of this study. However, the mean score on both purpose in life and life satisfaction which was somehow uncertain purpose in life and slightly satisfied with life among the motorcycle operators necessitates logotherapeutic interventions. Purpose in life is a driving force in life (Frankl, 1969) without which a person could possibly succumb to maladaptive emotions, cognition and behaviours. In fact, lack of clear purpose in life would possibly results into existential vacuum characterized by despair, aggression, addiction and depression. For example, without purpose in life, Frankl and some his companions in the concentration camps who had tasks to accomplish would not have achieved their dreams (Frankl, 


\section{International Journal of Social Science and Economic Research}

ISSN: 2455-8834

Volume:05, Issue:09 "September 2020"

1975). It follows necessarily that youth have a key obligation to set up goals in life which would gradually lead them to work towards achievement of purpose in life and life satisfaction.

In a similar way, this study is significant to parents, teachers and Kenyan government (Inclusive of County of governments) who has the role foster "purpose in life" among children and youth to aid to work towards achieving their "purpose in life" for "life satisfaction". For education system, this study found out that motorcycle operation is preferred by youth from all educational levels (Primary, secondary and college and above graduates). It is therefore important that the education system should enable child, adolescents and youth in learning institutions be aware of the three logotherapeutic values: creative, experiential and attitudinal values as they venture into different careers.

The questions about life are enormous and everything that exists search for life from whichever way it could be achieved. For example, Frankl (1968) without doubt in the concentration camp had the knowledge that his dear wife, child and parents were already dead, but he had a book (Doctor and the soul) that he desired to complete writing. Such a desire and experience helped him to create values and attitudes towards life which resulted to his completion of the desired book.

Psychoeducation for parents and school teachers should be carried out to enable them assist children, adolescents and youth to focus on their lives towards creating and fulfilling purpose in life. Finally there is great need to work towards establishing a tool that can measure purpose in life and life satisfaction taking into account the psychological, cultural and spiritual dimensions of life.

In the future, longitudinal research is needed on changes in purpose in life among motorcycle operators among the motorcycle operators with aim of establishing patterns of growth towards clear purpose in life and life satisfaction.

\section{REFERENCES}

Benard, B. (1991). Fostering resiliency in kids: Protective factors in the family, school and community. San Francisco: Werstern Regional Center for Drugs Free Schools and communities.

Brandstatter, M., Kogler, M., Baumann, U., Fensterer, V., Kuchenhoff, H., Borasio, G. D., \& Fegg, M. J. (2014). Experience of meaning in life in bereaved informal caregivers of palliative care patients. Support Care Cancer, 22(5), 1391 - 1399.

Cohen, S., Gottlieb, B. H., \& Underwood, L. G. (2001). Social relationships and health: Challenges for measurement and intervention. Advances in Mind Body Medicine, 17(2), 129 - 141. 
International Journal of Social Science and Economic Research

ISSN: 2455-8834

Volume:05, Issue:09 "September 2020"

Cohen, K., \& Cairns, D. (2012). Is searching for meaning in life associated with reduced subjective well-being? Confirmation and possible moderators. Journal of Happiness Studies, 13, 313-331. https://doi.org/10.1007/s10902-011-9265-7

Crumbaugh, J. C., \& Mahokick, L.T . (1969). Manual of instructions for purpose in life test (PIL). Munster: Psychometric Affiliates.

Damon, W. (2008). The path to purpose: How young people find their calling in life. New York, NY: The Free Press.

Damon, W., Menon, J., \& Bronk, K. C (2003). The development of purpose during adolescence.

Applied Development Science, 7(3), 119 - 128.

Diener, E., Emmons, R. A., Larsen, R. J., \& Griffin, S. (1985). The satisfaction with life scale. Journal of Personality Assessment, 49, 71-75.

Diener, E., Fujita, F., Tay, L., \& Biswas-Diener, R. (2012). Purpose, mood, and pleasure in predicting satisfaction judgements. Social Indicators Research, 105, 333 - 341.

Diener, E., Inglehart, R., \& Tay, L. (2013). Theory and validity of life satisfaction scales. Social Indicators Research, 112, 497 - 527.

Diener, E., Gohm, C. L., Suh, M., \& Oishi, S. (2000). Similarity of relation between marital status and subjective well- being across cultures. Journal of Cross- Cultural Psychology, 31, 419 - 436.

Diener, E., Oishi, S., \& Lucas, R. E. (2003). Personality, culture, and subjective well-being: Emotional and cognitive evaluations of life. Annual of Review of Psychology, 54, 403 - 425.

Diener, E., Suh, E., \& Oishi, S. (1997). Recent findings on subjective well-being. Indian Journal of Clinical Psychology, 24, 25 - 41.

Everett, S. A., Sults, R. A., Barrios, L. C., Sacks, J. J., Lowry, R., \& Oeltmann, J. (2001). Trends and subgroup differences in transportation related injury risk and safety behaviours among high school students. Journal of Adolescent Health, 28, 228 234

Frankl, V. (1959). Man's search for meaning. London: Hodder \& Stoughton.

Frankl, V. (1967). Psychotherapy and existentialism: Selected papers on logo therapy. New 


\section{International Journal of Social Science and Economic Research}

ISSN: $2455-8834$

Volume:05, Issue:09 "September 2020"

York, NY: Simon and Schuster.

Frankl, V. E. (1967). Psychotherapy and existentialism. New York: Washington Square press.

Frankl, V. E. (1969). The will to meaning: Foundations and applications of logo therapy. New York, NY: Meridian.

Frankl, V. E. (1973). The doctor and the soul. From psychotherapy to logo therapy. New York: Random House.

Frankl, V. E. (1975). The unconscious God. New York,NY: Simon and Schuster.

Frankl, V. E. (1978). The unheard cry for meaning: Psychotherapy and Humanism. New York, NY: Simon and Schuster.

Frankl, V. E. (1985). Man's search for meaning (Rev. ed). New York : Washington Square Press. Frankl, V. E. (1986). The doctor and the soul: From psychotherapy to logotherapy. New York,

NY: Vintage Books.

Frankl, V. E. (1988). The will to meaning: Foundations and applications of logotherappy. New York, NY: World.

Frankl, V. E. (1992). Man's search for meaning (4th ed.). Boston, MA: Beacon press.

Frankl, V. E. (2000). Recollections: An autobiography. New York, NY: Basic Books.

Fujita, M. (2013). The Japanese and Chinese models of industrial organization: competing for supremacy in the Vietnamese motorcycle industry. Discussion Paper No. 420. Institute of Developing Economies, Chiba.

Government of Kenya (GOK) (2007). Kenya Vision 2030. Ministry of Planning and National Development. The National Economic and Social council.

Government of Kenya (GOK). (2012) Economic Survey. Kenya National Bureau of Statistics. Nairobi: The government.

Government of Kenya (GOK). (2010). Kenya Demographic and Health Survey 2008-2009.

Nairobi: The government.

Hill, P. L. (2014). Purpose in life as a predictor across adulthood. Psychological Science, 25, $1482-1486$. 
International Journal of Social Science and Economic Research

ISSN: 2455-8834

Volume:05, Issue:09 "September 2020"

Kasaalita, W., \& Kibalama, J.. S. (2007). Deliveray of urban trannsport in developing countries; The case of motorcycle taxi service (boda boda) operation in Kampala. Development of South African Bank, 24, 2.

Kim, E. S., Sun, J. K., Kubzansky, L. D., Park, N., \& Peterson, C. (2013). Purpose in life and reduced risk of mycordial infraction among older U.S adults with coronary heart disease: A two-year follow-up. Journal of Behavioural Medicine, 36, 124 $-133$.

Kumar A. (2011). Understanding the important roles of motorcycle sector in African cities. Apolitical economy perspective. Sub-Saharan Africa Transport Program. World Bank.

Mannering, F. L. (1995). Statistical analysis of motorists' perceived accident risk. Accident Analysis and Prevention, 27(1), 21 - 31.

McKnight, P. E., \& Kashdan, T. B. (2009). Purpose in life as a system that creates and sustains health and well- being: An integrative, testable theory. Revised General Psychology, 13, 242- 251.

Mugenda, A. G., \& Mugenda, O. M. (2012). Research methods dictionary. Nairobi: Kijabe Press.

Odumosu, A. Y. (2008). Perception of motorcycle infrastructure provision and use in Abuja metroplis. Lagos: Institute of Transport Technology.

Oluranti, I. O. (2011). Informal self-employment and poverty alleviation: Empirical evidence from motorcycle taxi riders in Nigeria. International Journal of Economics and Finance, 3: 2.

Park, N., Park, M., \& Peterson, C. (2010). When is the search for meaning related to life satisfaction? Applied Psychology: Health and Well-Being, 2(1), 1-13. Doi:10.1111/j.1758-0854.2009.01024

Porter, G. (2013), "Urban transport in Cape Coast, Ghana: A social sustainability analysis". Case study prepared for Global Report on Human Settlements 2013.Available at: http://www.unhabitat.org/grhs/2013

Schemer, M. F., Wrosch, C., Baum, A., Cohen, S., Martire, L. M., Matthews, K. A., \& Zdaniuk,

B. (2006). The life engagement test: Assessing purpose in life. Journal of 
International Journal of Social Science and Economic Research

ISSN: 2455-8834

Volume:05, Issue:09 "September 2020"

Behavioral Medicine, 29, 291-298.

Siaya County Government. (2012). County integrated development plan 2013- 2017. Research and service County of Siaya

Veenhoven, R. (n.d.) (2015). The study of life satisfaction. Retrieved May 25, 2015, from http://www2.eur.nl/fsw/research/veenhoven/Pub1990s/96d

Wnuk, M., Marcinkowski, J. T., \& Fobair, P. (2012). The relationship and hope in shaping happiness among patients with cancer in Poland. Journal of Psychosocial Oncology, 30(4), 461- 483. 